\title{
OPTIMAL UNEMPLOYMENT INSURANCE DESIGN: Time Limits, MONITORING, OR WORKFARE?
}

\author{
PETER FREDRIKSSON \\ BERTIL HOLMLUND
}

CESIFO WORKING PAPER No. 1019

CAtegory 3: Social Protection

August 2003

An electronic version of the paper may be downloaded

- from the SSRN website:

www.SSRN.com

- from the CESifo website: www.CESifo.de 


\title{
OPTIMAL UNEMPLOYMENT INSURANCE DESIGN: Time Limits, MONITORING, OR WORKFARE?
}

\begin{abstract}
This paper analyses crucial design features of unemployment insurance (UI) policies. We examine three different means of improving the efficiency of UI: the duration of benefit payments, monitoring in conjunction with sanctions, and workfare. To that end we develop a quantitative model of equilibrium unemployment. The model features worker heterogeneity, which takes the form of differences in preferences for leisure. All the instruments are ways of limiting the duration of UI benefit receipt and the model can be used to compare them in a coherent fashion. The analysis suggests that a system with monitoring and sanctions restores search incentives most effectively, since it brings additional incentives to search actively so as to avoid the sanction. Therefore, the UI provider can offer a more generous UI replacement rate in a system with monitoring and sanctions than in the other two systems. Workfare appears to be inferior to the other two systems.
\end{abstract}

JEL Code: J64, J65, J68.

Keywords: unemployment insurance, search, monitoring, sanctions, workfare.

\author{
Peter Fredriksson \\ Department of Economics \\ Uppsala University \\ Box 513 \\ SE-75120 Uppsala \\ Sweden \\ Peter.Fredriksson@nek.uu.se
}

\author{
Bertil Holmlund \\ Department of Economics \\ Uppsala University \\ Box 513 \\ SE-75120 Uppsala \\ Sweden \\ Bertil.Holmlund@nek.uu.se
}

We are grateful to David Grubb for comments on an earlier draft. We also acknowledge useful comments from Per-Anders Edin, John Evans, Oskar Nordström Skans and seminar participants at the Ministry of Finance, Stockholm, the Institute for Labour Market Policy Evaluation (IFAU), Uppsala, and the University of Aarhus. The research has in part been supported by OECD's Directorate for Education, Employment, Labour and Social Affairs and by the Swedish Council for Working Life and Social Research (FAS). 


\section{Introduction}

Theoretical modeling of unemployment insurance (UI) has typically focused on the benefit level or the replacement rate, i.e., the fraction of earnings replaced by unemployment benefits. Of course, the design of an optimal UI system raises many other issues. For example, should there be a time limit on benefit receipt? To what extent should benefit recipients be induced to follow prescribed search requirements? Is there a case for a work requirement in exchange for benefits?

The present paper contributes to the welfare analysis of UI by analyzing three different means of improving the efficiency of UI. The first instrument is the duration of benefit payments, or more generally the time sequencing of benefits; the second is monitoring in conjunction with sanctions; and the third is workfare. The purpose is to offer a framework that allows a comparison of the three instruments in a coherent fashion. Needless to say, an exhaustive discussion of UI design should also consider other issues, such as modes of financing and entitlement rules, issues that are ignored in the present paper.

The question of time sequencing of benefits is about whether benefits should be paid at a fixed rate over the spell of unemployment or decline (or increase) over the spell. This issue appeared in the literature on optimal UI in the late 1970s and has attracted new attention in recent research. ${ }^{1}$ Issues regarding monitoring and sanctions concern how much resources should be spent on checking search behavior and how sanctions, such as benefit cuts, should be implemented if prescribed search requirements are not met. These questions have been discussed in policy circles but only rarely been the subject of research. ${ }^{2}$

Workfare - the requirement that a benefit recipient participate in some work activity in exchange for benefits - has been on the policy agenda for a very long time; indeed, examples of workfare in France and Britain can be traced centuries back (Besley and Coate, 1992).

\footnotetext{
${ }^{1}$ Shavell and Weiss (1979) is the seminal paper in this area. More recent studies include Hopenhayn and Nicolini (1997), Wang and Wiliamson (1996), Davidson and Woodbury (1997), Cahuc and Lehmann (2000) and Fredriksson and Holmlund (2001).

${ }^{2}$ Recent theoretical papers include Boone and van Ours (2000) and Boone et al. (2002). A growing number of empirical studies suggest that monitoring in conjunction with sanctions can have substantial behavioral effects. See Abbring et al. (1998), van den Berg et al. (1998) and Lalive et al. (2002) for evidence on the effects of sanctions. Several randomized experiments from the United States indicate that more stringent search requirements reduce the duration of benefit receipt (Johnson and Kleppinger, 1994; Benus and Johnson, 1997).
} 
Workfare has been scrutinized in the public finance literature on poverty alleviation (Besley and Coate 1992, 1995). In the context of UI, workfare has sometimes been discussed in conjunction with active labor market policies (Jackman, 1994). One idea in this discussion is that labor market programs can be useful to implement the work test of UI. Although the idea has been around for some time, it has not been subject to much rigorous formal analysis. ${ }^{3}$

In this paper we formulate a quantitative model of equilibrium unemployment within which each of the three policy instruments can be examined. The model extends the analyses of Fredriksson and Holmlund (2001), Boone and van Ours (2000), and Boone et al. (2002) by incorporating worker heterogeneity and by enlarging the set of policy instruments. Worker heterogeneity appears as differences in preferences for leisure. The motivation for this approach is the desire to shed light on the role of workfare as a screening device. When workers differ in their preferences for leisure, they will also differ with respect to their search effort. However, search effort is unobserved by the insurer - or at least observed imperfectly and UI benefits can therefore not be directly conditioned on search. If search indeed were observed one would expect that an optimal UI policy would reward active and penalize less active search. Workfare schemes may conceivably be useful as a means to encourage UI beneficiaries to engage in active job search. To our knowledge, no earlier study has systematically explored the performance of workfare in comparison to other conceivable policy instruments.

The next section presents the basic theoretical framework and Section 3 turns to the welfare analysis. This analysis suggests that a system with monitoring and sanctions restores search incentives most effectively, since it brings additional incentives to search actively so as to avoid the sanction. Therefore, the UI provider can offer a more generous UI replacement rate in a system with monitoring and sanctions than in the other two systems. Workfare appears to be inferior to the other two systems.

\footnotetext{
${ }^{3}$ The recent paper by Hansen and Tranæs (1999) is an exception. Several empirical studies have found support for the idea that workfare works as a screening device. The study by Black et al. (2003) indicates that the mere threat of being placed in a labor market program can reduce time spent on UI and boost job findings. The results reported by Benus and Kleppinger (1997) point in the same direction. Fredriksson and Holmlund (2003) offer a survey of recent literature on how to improve incentives in UI.
} 


\section{The Model}

The model extends the analysis in Fredriksson and Holmlund (2001) by incorporating individual heterogeneity. We consider heterogeneity in preferences for leisure, i.e. the same form of heterogeneity as Beaudry and Blackorby (1998) and Hansen and Tranæs (1999).

\section{$\underline{2.1 \text { Workers and Labor Market Transitions }}$}

We follow Hansen and Tranæs (1999) in assuming that there are only two types of individuals: workers $(w)$ and non-workers $(n)$. For an individual of type $i=w, n$, instantaneous utility is given by

$$
v_{i}^{j}=\ln c_{i}^{j}+\delta_{i} \ln \ell_{i}^{j}
$$

where $c$ denotes consumption and $\ell$ leisure. The marginal rate of substitution between consumption and leisure differs between workers and non-workers. In particular we assume that $\delta_{w}<\delta_{n}$. This difference in turn implies different levels of consumption and leisure for workers and non-workers. We will make the extreme assumption that non-workers do not search for a job unless the monetary compensation outside employment becomes unreasonably low.

There are four potential states $(j)$ : employment $(e)$, unemployment insurance (UI) receipt $(u)$, participation in workfare $(p)$, or unemployment assistance (UA) receipt (a). Associated with each state is a present discounted value, $V_{i}^{j}, j=e, u, p, a$.

To preserve tractability we assume that consumption equals income in each instant, i.e., individuals cannot save or borrow. A representative employed worker thus consumes income from work, $c_{i}^{e}=w$, and enjoys a fixed amount of leisure, $\ell_{i}^{e}=\bar{\ell} .{ }^{4}$ An individual on UI consumes $c_{i}^{u}=b w$, where $w$ is the aggregate wage, and enjoys leisure of $\ell_{i}^{u}=1-s_{i}^{u}$ (the time constraint has been normalized to unity). An individual on workfare consumes $c_{i}^{p}=b w$ of goods and $\ell_{i}^{p}=1-p-s_{i}^{p}$ of leisure; the tasks required in workfare "taxes" away $p$ units of leisure time. Finally, an individual on unemployment assistance consumes $c_{i}^{a}=z w$ of goods

\footnotetext{
${ }^{4}$ We refer to $w$ as the wage although it is in fact wage income, i.e., the wage rate times hours of work. If workers choose their working time, taking the hourly wage as given, work-hours - and thus leisure - during employment will be independent of the wage. In particular, leisure will be given by $\ell_{w}^{e}=\delta_{w} /\left(1+\delta_{w}\right)$.
} 
and $\ell_{i}^{a}=1-s_{i}^{a}$ units of leisure. We take compensation on UI and workfare to be greater than unemployment assistance (UA), i.e., $b \geq z$.

An employed worker is separated from his job at an exogenous Poisson rate, $\phi$. A spell of employment immediately qualifies for UI benefits. The job offer arrival rate for individuals outside employment depends on search intensity and the aggregate state of the market. For individuals in state $k=u, p, a$, job offers arrive at the rate $s_{i}^{k} \alpha$. The offer arrival rate conditional on search, $\alpha$, is a market variable that we endogenize later on. Notice that nonworkers do not search and hence $s_{n}^{k}=0$. Finally, UI recipients are transferred to UA or workfare at the rate $\mu \pi\left(s_{i}^{u}\right)$. We interpret this transition rate below.

Having defined the relevant transition rates and the compensation in each state we can write the value functions for an individual of type $i$ as follows

$$
\begin{gathered}
r V_{i}^{e}=v_{i}^{e}+\phi\left(V_{i}^{u}-V_{i}^{e}\right) \\
r V_{i}^{u}=v_{i}^{u}+s_{i}^{u} \alpha\left(V_{i}^{e}-V_{i}^{u}\right)+\mu \pi\left(s_{i}^{u}\right)\left[\max \left(V_{i}^{p}, V_{i}^{a}\right)-V_{i}^{u}\right] \\
r V_{i}^{p}=v_{i}^{p}+s_{i}^{p} \alpha\left(V_{i}^{e}-V_{i}^{p}\right) \\
r V_{i}^{a}=v_{i}^{a}+s_{i}^{a} \alpha\left(V_{i}^{e}-V_{i}^{a}\right)
\end{gathered}
$$

where $r$ is the subjective rate of time preference. Equations (2)-(5) embody the assumptions that time is continuous and individuals have infinite horizons.

The three institutions that we consider come out as special cases of equation (3). Consider first the system with time limits. A convenient way of parameterizing such a system is as follows: Write the stochastic termination rate as being independent of $s_{i}^{u}$, i.e., $\pi\left(s_{i}^{u}\right)=1$ and restrict $p$ such that $\max \left(V_{w}^{p}, V_{w}^{a}\right)=V_{w}^{a}$, i.e., workers prefer UA over workfare. In this incarnation, the model features stochastic duration of benefit receipt; the expected duration of unemployment insurance receipt is thus $(1 / \mu)$. Using this modeling strategy we avoid the non-stationarities associated with fixed duration that complicates the model without adding much insight; see Fredriksson and Holmlund (2001).

Consider next the system with monitoring and sanctions. Recipients of UI benefits are monitored with respect to their search behavior at the Poisson rate $\mu$. Monitoring is a random inspection of an individual's search activity. Given monitoring, there is some probability that 
the observed search effort does not meet the search requirement, in which case the worker is sanctioned and transferred to state $a$. Thus, $\pi\left(s_{i}^{u}\right)$ is the probability of being sanctioned per unit time given that the individual is monitored and supplies $s_{i}^{u}$ units of search. In sum, the system with monitoring and sanctions is parameterized as follows: the termination rate of UI benefit receipt is a decreasing function of search, $\partial \pi\left(s_{i}^{u}\right) / \partial s_{i}^{u} \leq 0$, and $p$ is set such that $\max \left(V_{w}^{p}, V_{w}^{a}\right)=V_{w}^{a}$.

For practical purposes, we choose $\pi\left(s_{i}^{u}\right)=1-\sigma s_{i}^{u}$ as our parameterization of the sanctioning probability. To ensure that $\pi$ is a proper probability, we take $\sigma$ to be bounded by the unit interval, that is, $0 \leq \sigma \leq 1$. This restriction implies that there is a positive probability of being sanctioned for all values of $s_{i}^{u}$. In other words the monitoring technology is plagued by Type II errors - some complying individuals are sanctioned. The parameter $\sigma$ measures to which extent the sanction probability depends on an agent's own search effort. One way to interpret $\sigma$ is that it indexes the precision of the inspection technology. A simple example may illustrate why it is useful to think of $\sigma$ as an indicator of the precision of the inspection technology. Consider the extreme case when $\sigma=0$. This case mirrors the situation where benefit administrators roll a dice to determine whether the monitored individual has searched to rule or not. The inspection technology is thus completely random from the job searcher's perspective. In this case, the monitoring and sanctions system is equivalent to our incarnation of a system with finite duration of UI benefit receipt. We can therefore meaningfully compare the two systems by changing one parameter.

Consider finally a system with workfare. Individuals are randomly subjected to a work test at rate $\mu$. Given an offer to participate in workfare, they choose $\max \left(V_{i}^{p}, V_{i}^{a}\right)$. For a workfare system to be operative it must be true that $\max \left(V_{w}^{p}, V_{w}^{a}\right)=V_{w}^{p}$ and $\max \left(V_{n}^{p}, V_{n}^{a}\right)=V_{n}^{a}$. That is, the time requirement should be set such that workers opt for workfare while non-workers prefer unemployment assistance. Thus a workfare system is defined by $\pi\left(s_{i}^{u}\right)=1$ and the selfselection constraints $V_{w}^{p}>V_{w}^{a}$ and $V_{n}^{p} \leq V_{n}^{a}$.

Workers determine search in an atomistic fashion, i.e., by taking all wages and the offer arrival rate conditional on search, $\alpha$, as given. In general, optimal search for individuals on UI satisfies 


$$
\frac{\delta_{w}}{1-s_{w}^{u}}=\alpha\left(V_{w}^{e}-V_{w}^{u}\right)+\mu \sigma\left(V_{w}^{u}-V_{w}^{a}\right)
$$

The left-hand-side of (6) represents the marginal cost of search, that is, the marginal utility of leisure, while the right-hand-side constitutes the marginal return to search. The marginal return has two components: the first term refers to an increase in the job offer arrival rate and the second term to a reduction in the transition rate to UA. The systems with a time limit and workfare have $\sigma=0$, so the second component never appears in the marginal return to search. Optimal search for individuals in the remaining two states, $m=p, a$, is given by

$$
\frac{\delta_{w}}{1-s_{w}^{m}}=\alpha\left(V_{w}^{e}-V_{w}^{k}\right)
$$

Non-workers do not search at all so for them it must be true that $\delta_{n}$ is strictly greater than the marginal return to search in each state.

We restrict attention to a steady state environment. For workers there are flow equilibrium constraints that define the rates of employment and unemployment in the working population. For instance, the employment rate among workers is given by

$$
e_{w}=\frac{\alpha\left[\lambda_{w}^{u} s_{w}^{u}+I\left(V_{w}^{p}>V_{w}^{a}\right) \lambda_{w}^{p} s_{w}^{p}+I\left(V_{w}^{p} \leq V_{w}^{a}\right) \lambda_{w}^{a} s_{w}^{a}\right]}{\phi+\alpha\left[\lambda_{w}^{u} s_{w}^{u}+I\left(V_{w}^{p}>V_{w}^{a}\right) \lambda_{w}^{p} s_{w}^{p}+I\left(V_{w}^{p} \leq V_{w}^{a}\right) \lambda_{w}^{a} s_{w}^{a}\right]}
$$

where $I(\cdot)$ is the indicator function $(I(\cdot)=1$ if the expression within parenthesis is true) and $\lambda_{w}^{j}$ is the number of workers in state $j$ relative to non-employment: $\lambda_{w}^{j}=u_{w}^{j} /\left(1-e_{w}\right)$.

\subsection{Matching and Wage Determination}

The equilibrium in the model has an endogenous wage ( $w)$ and an endogenous offer arrival rate conditional on search $(\alpha)$. We endogenize $w$ and $\alpha$ by specifying a matching technology and a wage bargaining model. With respect to the matching technology we make the standard assumptions that the matching function $h=h\left(\bar{s}_{w}, v\right)$ is of the constant returns to scale variety and is increasing in both arguments. The "inputs" to the production of matches are the 
effective numbers of searchers $\bar{s}_{w}=s_{w}^{u} u_{w}^{u}+I\left(V_{w}^{p}>V_{w}^{a}\right) s_{w}^{p} u_{w}^{p}+I\left(V_{w}^{p} \leq V_{w}^{a}\right) s_{w}^{a} u_{w}^{a}$ and the number of vacancies $(v)$. The probability of finding a job conditional on search is then $\alpha(\theta)=h\left(\bar{s}_{w}, v\right) / \bar{s}_{w}=h(1, \theta)$, where $\theta \equiv\left(v / \bar{s}_{w}\right)$ is a measure of labor market tightness. Firms fill vacancies at the rate $q(\theta)=h\left(\bar{s}_{w}, v\right) / v=h(1 / \theta, 1)$. It is straightforward to verify that $\alpha^{\prime}(\theta)>0$ and $q^{\prime}(\theta)<0$, i.e. the tighter the market the easier it is for workers to find jobs and the more difficult it is for firms to find workers.

Wages are determined in individual bargaining between the worker and the firm. To determine the outcome of the wage bargain we must also specify firm values. The government finances unemployment expenditure by a proportional payroll tax $(\tau)$ levied on firms. Labor productivity is constant and given by $y$. The cost of holding a vacancy open is $\kappa y$, with $\kappa>0$. The value functions take the usual form

$$
\begin{gathered}
r J^{v}=-\kappa y+q(\theta)\left(J^{e}-J^{v}\right) \\
r J^{e}=y-w(1+\tau)-\phi\left(J^{e}-J^{v}\right)
\end{gathered}
$$

where $J^{v}$ is the asset value of a vacant job and $J^{e}$ the asset value of an occupied job. Since there is no cost of entering and exiting the vacancy market, a free entry condition, $J^{v}=0$, determines the number of vacancies in the market. From the free entry condition we obtain the wage cost, $w_{c} \equiv w(1+\tau)$, as proportional to the marginal product of labor: $w_{c}=[1-(r+\phi)(\kappa / q(\theta))] y \equiv d(\theta) y$. We refer to $w_{c}=d(\theta) y$ as the zero-profit condition. It specifies a negative relationship between $w_{c}$ and $\theta, d^{\prime}(\theta)<0$, since wage costs have to be lower in a tighter market in order to be consistent with zero profits.

Now consider wage determination. Given that bargaining is conducted at the individual level, the wage is given by $w=\arg \max \left[V_{w}^{e}(w)-V_{w}^{u}\right]^{\beta}\left[J^{e}(w)-J^{v}\right]^{1-\beta}, \beta \in(0,1)$. Imposing symmetry and the equilibrium condition, $J^{v}=0$, we write the outcome of the wage bargain as

$$
V_{w}^{e}-V_{w}^{u}=\frac{\beta}{1-\beta} \frac{J^{e}}{w_{c}}
$$


The model has a convenient recursive structure where the zero-profit condition and equation (11) determine $\theta$ and $w_{c}$. To see this, note that free entry of vacancies implies $J^{e}=\kappa y / q(\theta)$. The right-hand side of (11) is thus increasing in $\theta$ but independent of $s_{w}^{j}$. The left-hand side of (11) is also a function of $\theta$. But it is independent of $w$, given our chosen utility function and constant replacement rates. Moreover, it can be shown that it is independent of $s_{w}^{j}$ when the first-order condition for optimal search is invoked. With tightness determined, we get $s_{w}^{j}$ from (6) and (7), recognizing that the wage does not affect the differences in present values. With $\theta$ and $s_{w}^{j}$ determined, we get unemployment and employment rates from the flow equilibrium conditions. As we have set up the model, taxes do not affect search and unemployment.

\section{$\underline{2.3 \text { Welfare }}$}

We are interested in Pareto optimal UI policies. The objective of the UI provider is to maximize the expected utility of workers subject to non-workers receiving at least a minimum amount of utility. Thus, the welfare objective is

$$
W_{w}=e_{w} v_{w}^{e}+u_{w}^{u} v_{w}^{u}+I\left(V_{w}^{p}>V_{w}^{a}\right) u_{w}^{p} v_{w}^{p}+I\left(V_{w}^{p} \leq V_{w}^{a}\right) u_{w}^{a} v_{w}^{a}
$$

This is the relevant objective if there is no discounting because then firm values are irrelevant. We ignore discounting in order to validly compare alternative steady states without considering the adjustment process.

The final piece of the model is the government budget constraint. In general, it takes the form

$$
\gamma \tau w e_{w}=\gamma\left[b w u_{w}^{u}+C(\cdot)+I\left(V_{w}^{p}>V_{w}^{a}\right) b w u^{p}+I\left(V_{w}^{p} \leq V_{w}^{a}\right) z w\right]+(1-\gamma) z w
$$

where $\gamma$ is the worker share of the population. The left-hand-side of (14) represents the revenues from the payroll tax. The right-hand-side constitutes unemployment expenditure. The first component, in square brackets, refers to unemployment expenditure in relation to the 
worker population and the second component is compensation paid to non-workers. $C(\cdot)$, the real resource cost of running the monitoring and sanctions system, is assumed to be given by

$$
C=c(\sigma) \mu w u_{w}^{u}
$$

where $c(\sigma) \geq 0, c^{\prime}(\sigma)>0$ and $c(0)=0$, is the marginal cost of monitoring. Costs are increasing in the number of monitored individuals; the sanction itself commands no resources. As argued above, $\sigma$ can be interpreted as indexing the precision of the inspection technology. We take the marginal cost of monitoring to be increasing in $\sigma$; thus a more precise technology requires greater effort on the part of those who monitor search behavior.

Before proceeding to the numerical results let us ask the question: Is worker search behavior optimal from society's point of view? The answer is that, as long as it is optimal to provide some insurance to the unemployed, search intensity will be too low in equilibrium. The reason is that there is a tax base effect of increasing search. If all individuals supplied additional search, employment would increase and, consequently, the tax that finances a given unemployment insurance system would be lower. Everyone would gain from a lower tax rate since the consumption wage would be higher. This effect is not taken into account in the private determination of search; see Fredriksson and Holmlund (2001) for details. Indeed this is the rationale for introducing two of the policy instruments that we consider below.

\subsection{Calibration of the Model}

We take a quarter as the basic time unit and calibrate the model for a uniform benefit system, i.e., one that has $b=z$. We set the uniform wage replacement rate to 30 percent, which approximately corresponds to uniform characterization of the US unemployment benefit system; see Fredriksson and Holmlund (2001). The marginal product of labor is normalized to unity. The matching function is of the Cobb-Douglas variety: $h=a \bar{s}_{w}^{\eta} v^{1-\eta}$. We set $a=1.28$ and $\eta=0.5$; the latter is at the upper end of the estimates in Blanchard and Diamond (1989). We set the bargaining parameter to $\beta=\eta$, which is the optimal value if there would be no policy interventions; see Hosios (1990). 
The remaining parameters, $\kappa, \phi$, and $\delta_{w}$, are calibrated with respect to the working population. The calibration is such that the unemployment rate is 6.5 percent, unemployment duration is one quarter, and the partial equilibrium elasticity of the hazard to employment with respect to benefits equals 0.5 . These calibration points are broadly in line with the recent US experience.

We also need to assign some values for the number of workers $(\gamma)$ and $\delta_{n}$. We think of the potential labor force as consisting of two groups of individuals. A fraction $\gamma$ has a relatively low preference for leisure and therefore finds it worthwhile to search when out of work. Workers in this category constitute the "effective" labor force. The remaining fraction has a high preference for leisure and does not search. Somewhat arbitrarily, we assume that the ratio between the effective and the potential labor force is $0.95 .{ }^{5}$ To assign a value $\delta_{n}$ we assumed that non-workers would be willing to search only if $b=z \leq 0.1$. The exact value of $\delta_{n}$ is only relevant when designing a system with workfare.

To calculate the numbers for the monitoring and sanctions system we need an estimate of $c(\sigma)$ in (15). We used Swedish data and performed the following calculation to get a reasonable number for this parameter. In Sweden, the employment offices monitor job search. Job counselors devote around 30 percent of their time to meetings with job searchers; see Lundin (2000). The number of employees at the employment offices is approximately equal to 0.25 percent of the labor force. Therefore, we took $0.3 \times 0.0025=0.00075$ as an estimate of the real resource cost of the monitoring and sanctions system relative to GDP. Thus $c(\sigma) \mu u_{w}^{u}$ should equal 0.00075. According to Lundin (2000), public employment service officers on average have close to two meetings with an unemployed per quarter. If we set $\mu=2$ and $u_{w}^{u}=0.05$, this implies that $c(\sigma) \approx 0.0075$. To proceed we must specify the marginal cost function. We take a simple linear cost function $c(\sigma)=\psi \sigma$ and use $\psi=0.02$ when we calculate the numbers for the monitoring and sanctions system. It seems to us that this is a fairly large value for the marginal cost of monitoring. Still we prefer a "conservative" number

\footnotetext{
${ }^{5}$ Existing labor force surveys include various measures of "disguised" unemployment. One category, referred to as "latent job seekers" in Sweden, consists of non-participants reporting to be willing and able to work although they do not fulfill the search criteria for being classified as unemployed. Over the period 1995-2002, the ratio between the official and the potential labor force (the latter including latent job seekers) was 0.96 in Sweden.
} 
since there is genuine uncertainty about the value of this parameter. Table 1 summarizes the baseline parameters and Table 2 shows some key outcomes in the baseline calibration with a uniform benefit system.

Table 1: Baseline parameters

\begin{tabular}{ll}
\hline \hline Description & Parameter \\
\hline \hline Matching technology: $h=a \bar{s}^{\eta} v^{1-\eta}$ & $a=1.282335$ \\
& $\eta=0.5$ \\
Distribution of individuals and leisure values: & $\gamma=0.95$ \\
& $\delta_{w}=0.776489$ \\
& $\delta_{n}=2.646591$ \\
Marginal product of labor & $y=1$ \\
Vacancy cost & $\kappa=1.111860$ \\
Separation rate & $\phi=0.069519$ \\
Share parameter in the wage bargain & $\beta=0.5$ \\
Marginal cost of monitoring: $c(\sigma)=\psi \sigma$ & $\psi=0.02$ \\
\hline \hline
\end{tabular}

\section{A Comparison of the Three Policy Instruments}

\subsection{The Uniform Benefit System}

The baseline calibration features an unemployment rate among workers $\left(u_{w}^{u}\right)$ of 6.5 percent and unemployed individuals spend 61 percent of their time searching for a job; see $s_{w}^{u}$. Wages (net of taxes) are lower than the marginal product of labor because of search frictions. In the baseline calibration, the wage $(w)$ amounts to 89 percent of the marginal product of labor.

How does search respond to changes in the UI replacement rate? Since an increase in the replacement rate decreases the gain of finding employment, individuals respond by searching less when UI becomes more generous. As we shall see later, however, this is not necessarily true when we consider more general UI systems than the one paying a constant wage replacement rate indefinitely. 
Table 2: Baseline calibration and a benefit system with time limits

\begin{tabular}{lll}
\hline \hline & $(1)$ & $(2)$ \\
& Baseline & Optimal system with time limits \\
\hline \hline Policy variables & & \\
$b$ & 0.3 & 0.4621 \\
$z$ & -- & 0.3016 \\
$\mu$ & -- & 0.5 \\
$\tau$ & 0.0377 & 0.0538 \\
Economic outcomes & & \\
$s_{w}^{u}$ & 0.6081 & 0.4880 \\
$s_{w}^{a}$ & -- & 0.6099 \\
$u_{w}^{u}$ & 0.0650 & 0.0529 \\
$u_{w}^{a}$ & -- & 0.0300 \\
$w$ & 0.8891 & 0.8844 \\
$\varepsilon$ & -- & $0.55 \%$ \\
\hline \hline
\end{tabular}

Notes: Superindex $u$ and $a$ refer to UI and UA respectively. Remaining symbols in the table are explained in the main text. In the system with time limits $\mu$ is fixed at 0.5 . The change in welfare is measured relative to the base run.

We consider Pareto optimal benefit policies and assume that the UI provider maximizes the expected utility of workers subject to the constraint that non-workers receive at least a minimum amount of utility. The UI provider knows the distribution of workers and nonworkers in the population but it cannot tell if an individual is a worker or a non-worker. In addition to providing insurance, an optimally designed UI system should ideally screen out non-workers and increase the search intensity among workers.

Suppose that the base run defines the minimum utility of non-workers, i.e., $v_{n}^{u}=\ln z w=0.3 \times 0.8891$; see column 1 in Table 1 . Can we design an optimal uniform benefit system that is different from the base run? The answer to this question is no. The reason is that with only the wage replacement rate as an instrument it is impossible to separate the two types. The wage replacement rate is tied down to 30 percent because of the minimum utility constraint. 


\subsection{Time Limits in Benefit Receipt}

Consider now the case with time limits on UI benefit receipt. The search intensity among workers depends on whether she is insured or non-insured (i.e. on UA). If $b \geq z$, it is straightforward to verify that $s_{w}^{u} \leq s_{w}^{a}$, that is, a worker searches less intensively when receiving UI (indexed by $u$ ) compared to UA (indexed by $a$ ). The intuition is simply that search intensity while receiving UI is lower because there is a smaller gain associated with finding employment.

What happens to search in each state when we change the replacement rates? With respect to $z$ the model works much the same as before: search intensity is falling in the generosity of unemployment assistance. However, there is a differential effect of the UI replacement rate. An increase in $b$ reduces the search intensity of the insured, but increases the search intensity of the non-insured. The latter effect is the entitlement effect, first highlighted by Mortensen (1977). Those on UA search harder when UI becomes more generous since employment is a prerequisite for receiving UI. Since there is a tax base effect associated with search, an optimal benefit system exploits the entitlement effect by introducing finite duration of UI receipt (see Fredriksson and Holmlund, 2001).

We now conduct the following experiment. The expected duration of UI benefit receipt is fixed to six months, which implies $\mu=0.5$. An expected duration of six months corresponds to the duration of UI receipt in the US. Then we solve for the optimal benefit system by choosing $b$ and $z$ such that the expected utility among workers is maximized subject to the minimum utility constraint for non-workers, the budget constraint, and the market equilibrium constraints.

In Figure 1 we plot welfare for workers at different values of the relative reduction in the monetary compensation when UI expires, $(b-z) / b$. If there is no reduction in the monetary compensation, the model is formally equivalent to a uniform benefit system as there is no penalty associated with losing the entitlement to UI. However, as shown in the figure, such a system is not optimal. An optimal system implies that benefits should be reduced by 35 percent when UI expires. 
Figure 1: Worker expected utility and the "penalty" of UI expiration.

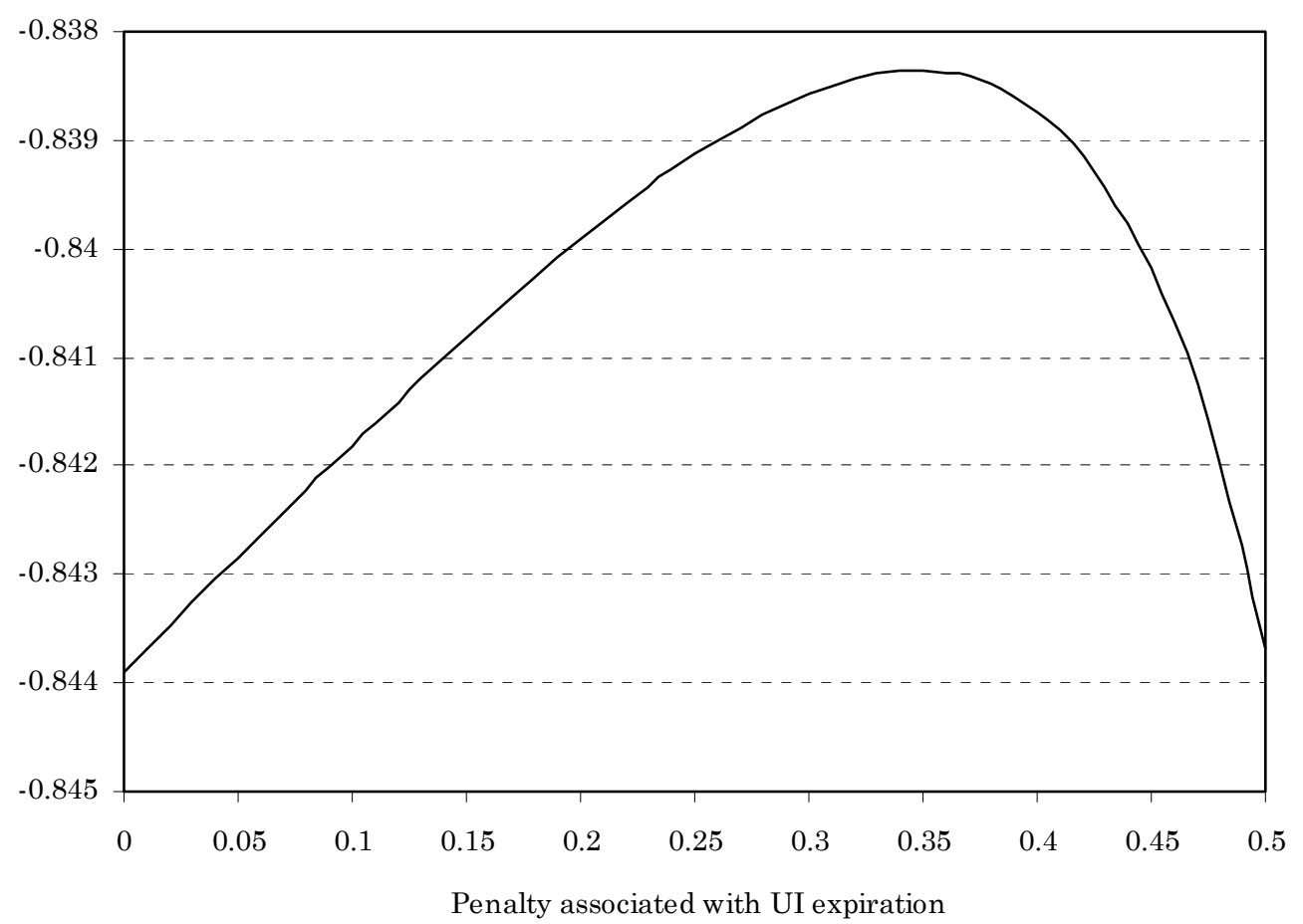

In column 2 of Table 2 we present the implications of the optimal system with time limits. The optimal system with time limits gives workers substantially more insurance than the base run. The UI replacement rate amounts to 46 percent of the wage. Since compensation is more generous, search intensity decreases while receiving UI. Notice also that total unemployment $\left(u_{w}^{u}+u_{w}^{a}\right)$ and taxes increase.

As a measure of the change in welfare implied by a move to the optimal system we consider the consumption tax $(\varepsilon)$ that would make workers indifferent between living in the optimal system and the base run. ${ }^{6}$ As shown by the last row in Table 1, they would be willing to pay 0.55 percent of consumption to live in the optimal system with time limits.

\footnotetext{
${ }^{6}$ The consumption tax is equivalent to the change in welfare. To illustrate this, consider two candidate policies 0 and 1. Let $\hat{W}_{1}(\varepsilon)$ denote welfare after the imposition of the consumption tax and $W_{0}$ denote welfare without the $\operatorname{tax}$. The consumption tax that makes workers indifferent between the two systems is defined by the solution to $\hat{W}_{1}(\varepsilon)=W_{0}$. Because of our utility function, $\varepsilon$ solves $W_{1}+\ln (1-\varepsilon)=W_{0}$. If $\varepsilon$ is small, we have $\ln (1-\varepsilon) \approx-\varepsilon$ and therefore $\varepsilon \approx W_{1}-W_{0}$.
} 


\section{$\underline{3.3 \text { Monitoring and Sanctions }}$}

In this section we make the following policy experiment. Again we fix $\mu$ to 0.5 such that unemployed workers on average are monitored every second quarter. Then we choose $b, z$, and $\sigma$ optimally in the same way as we did above.

There are two behavioral implications of introducing a system with monitoring and sanctions. First of all, for given wage replacement rates, UI recipients will search harder since an increase in search reduces the risk of being sanctioned and transferred to UA receipt. Second, workers will bargain more aggressively. This is because there will be a reduction in the transition rate to UA receipt given search intensity. In the system with time limits, the transition rate is $\mu$; in the monitoring and sanctions system it is $\mu\left(1-\sigma s_{w}^{u}\right)$. The reduction of the transition rate to the least favored state yields an improvement of workers' outside opportunities. Therefore, workers bargain more aggressively - wage costs increase and fewer jobs are created. All in all, the policy experiment thus has two opposing effects on employment - search increases but at the same time wage pressure rises - and the employment effect of the policy is a priori ambiguous.

Figure 2 presents an analogous graph as Figure 1. It plots the expected utility of workers for different values of the relative monetary sanction, $(b-z) / b$, when being transferred to UA. The graph is derived holding $\sigma$ constant at its optimal value. We plot the graph as long as welfare is higher than in the base run. We see that there is an interior solution featuring monitoring and sanctions. Also by comparing the welfare scales of Figures 1 and 2 we see that a system with monitoring and sanctions delivers higher expected utility for workers than the system with time limits. 
Figure 2: Worker expected utility and the monetary sanction.

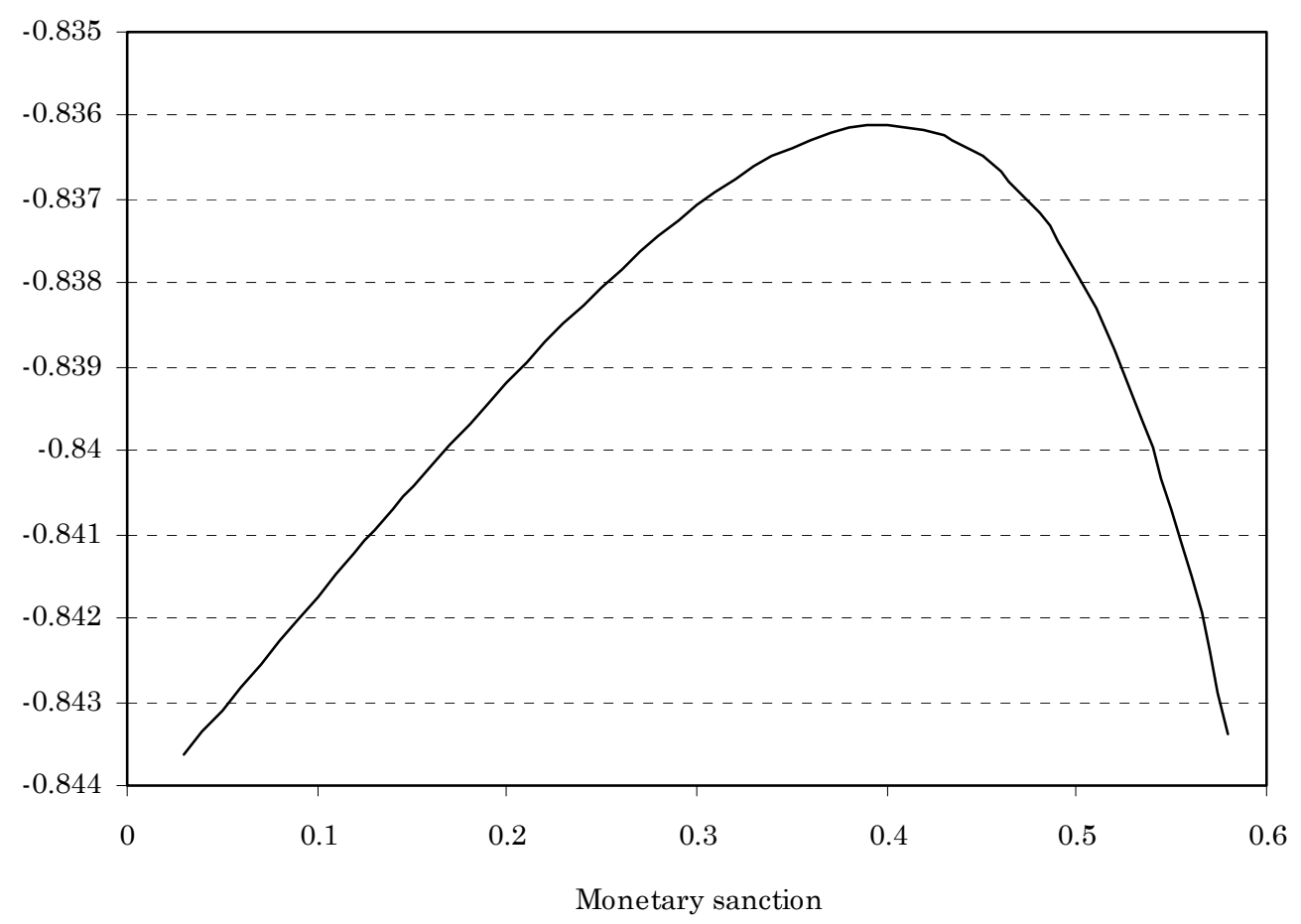

In column 2 of Table 3 we report a set of outcomes pertaining to the system with monitoring and sanctions. For ease of comparison we give the outcomes with time limits in column 1. The outcome of this policy experiment is that the UI provider should always opt for a precise technology, i.e., $\sigma=1$. Presumably, this result is driven by the assumed cost structure. Therefore, we are reluctant to place a lot of emphasis on the exact value for $\sigma$. Nevertheless, in Boone et al. (2002) we conclude that the introduction of a system with monitoring and sanction is a welfare improvement relative to a system with time limits for reasonable values of monitoring costs. These costs would have to be implausibly high in order for this conclusion not to hold. So we are reasonably comfortable in the conclusion suggested by the last line of Table 2, i.e., that workers would be willing to pay more to live in the an optimal system with monitoring and sanctions than in a system with time limits.

With monitoring and sanctions, the UI provider can afford to be more generous to UI recipients. The UI replacement rate equals 50 percent in a system with monitoring and sanctions; the corresponding number with time limits is 46 percent. Despite the fact that 
search intensity increases, unemployment increases with monitoring and sanctions. This has to do with the adverse effect on wage setting induced by an improvement in workers' outside option. Workers' outside options increase both because the UI replacement rate is higher but also because the introduction of monitoring and sanctions improves workers bargaining position. Since wage costs increase firms respond by creating fewer vacancies.

Table 3: A benefit system with monitoring and sanctions

\begin{tabular}{lll}
\hline \hline & $(1)$ & $(2)$ \\
& Time limits & Monitoring and sanctions \\
\hline \hline Policy variables & & \\
$B$ & 0.4621 & 0.5045 \\
$Z$ & 0.3016 & 0.3027 \\
$\mu$ & 0.5 & 0.5 \\
$\sigma$ & 0 & 1 \\
$\tau$ & 0.0538 & 0.0635 \\
Economic outcomes & & \\
$s_{w}^{u}$ & 0.4880 & 0.5000 \\
$s_{w}^{a}$ & 0.6099 & 0.6106 \\
$u_{w}^{u}$ & 0.0529 & 0.0689 \\
$u_{w}^{a}$ & 0.0300 & 0.0211 \\
$W$ & 0.8844 & 0.8812 \\
$\varepsilon$ & $0.55 \%$ & $0.78 \%$ \\
\hline \hline
\end{tabular}

Notes: Superindex $u$ and $a$ refer to UI and UA respectively. Remaining symbols are explained in the main text. $\mu$ is fixed at 0.5 . The welfare changes are measured relative to the base run.

\subsection{Workfare}

Consider, finally, how the system works with workfare. We think of a world where employment officers administer a "work test" randomly at rate $\mu$. If the unemployed worker enters workfare she is required to perform some duties $(p)$ that reduce the time available for other activities; hence, leisure while participating in workfare is given by $\ell_{w}^{p}=1-p-s_{w}^{p}$. In exchange for these duties she gets to keep the UI benefit.

As noted by Hansen and Tranæs (1999), workfare is potentially a welfare improving screening device. Consider a benefit system that is uniform initially, i.e., $b=z$. Since preferences for leisure are private information to the individuals, both workers and non- 
workers will claim and receive benefits. Imagine now that workfare is introduced as a requirement for benefit receipt along with a slight increase in UI while keeping UA fixed. The welfare of non-workers is not affected as long as they avoid workfare and prefer not to search. The welfare of workers may well increase since they care less about the reduction in leisure associated with workfare.

Appropriately designed workfare must satisfy two self-selection constraints. If workfare acts as a screen, it should not be optimal for workers and non-workers to mimic each other. Thus UI-cum-workfare must be at least as good as UA for workers, i.e., $V_{w}^{p} \geq V_{w}^{a}$ Analogously, UA must be at least as good as UI-cum-workfare for non-workers, i.e., $V_{n}^{a} \geq V_{n}^{p}$. If it is optimal for workers to opt for UA rather than workfare, then the model is formally equivalent to the system with time limits. So the defining constraint on a system with workfare is that it must not be optimal for non-workers to mimic workers.

If non-workers mimic workers, then it will never be optimal to require workfare. The reason is that in this case workfare fulfils no screening function, it only imposes costs on workers and non-workers. Since the time requirement in workfare $(p)$ imposes costs on workers, the Pareto optimal policy featuring workfare will be such that the incentive compatibility constraint is binding, $V_{n}^{a}=V_{n}^{p}$.

If there is an equilibrium with workfare, then no worker will ever be transferred to unemployment assistance. Only non-workers will end up on UA. In this sense workfare is the perfect screening device. However, workfare is not conducive to search since there is a reduction in the available leisure time. Hence, it is not obvious that workfare will raise the expected utility of workers relative to the case with time limits. Moreover, the existence of a system with workfare depends crucially on whether the difference in terms of preferences for leisure is sufficiently large between workers and non-workers; see Hansen and Tranæs (1999). Thus it not clear that a system with workfare dominates a uniform benefit system, either.

Now consider the following policy experiment. We fix $\mu$ to 0.5 implying that the unemployed are given an offer to participate in workfare once every second quarter. Then we choose $b, z$, and $p$ optimally in the same fashion as above. The leisure value for non-workers 
is calibrated so that they would search for a job if $b \leq 0.1$ in the uniform system. The ratio between the two leisure values is $\delta_{n} / \delta_{w} \approx 3.4$.

Figure 3 graphs the expected utility of workers as a function of the time requirement in workfare $(p)$. We plot the expected utility as long as it is greater than the expected utility in the base run. If $p=0$, workers get the same expected utility as in the base run. Given our assumption about $\delta_{n}$, it turns out that there is an interior solution with workfare. However, the welfare scale suggests that workfare does not outperform time limits.

Figure 3: Worker expected utility and the time requirement in workfare.

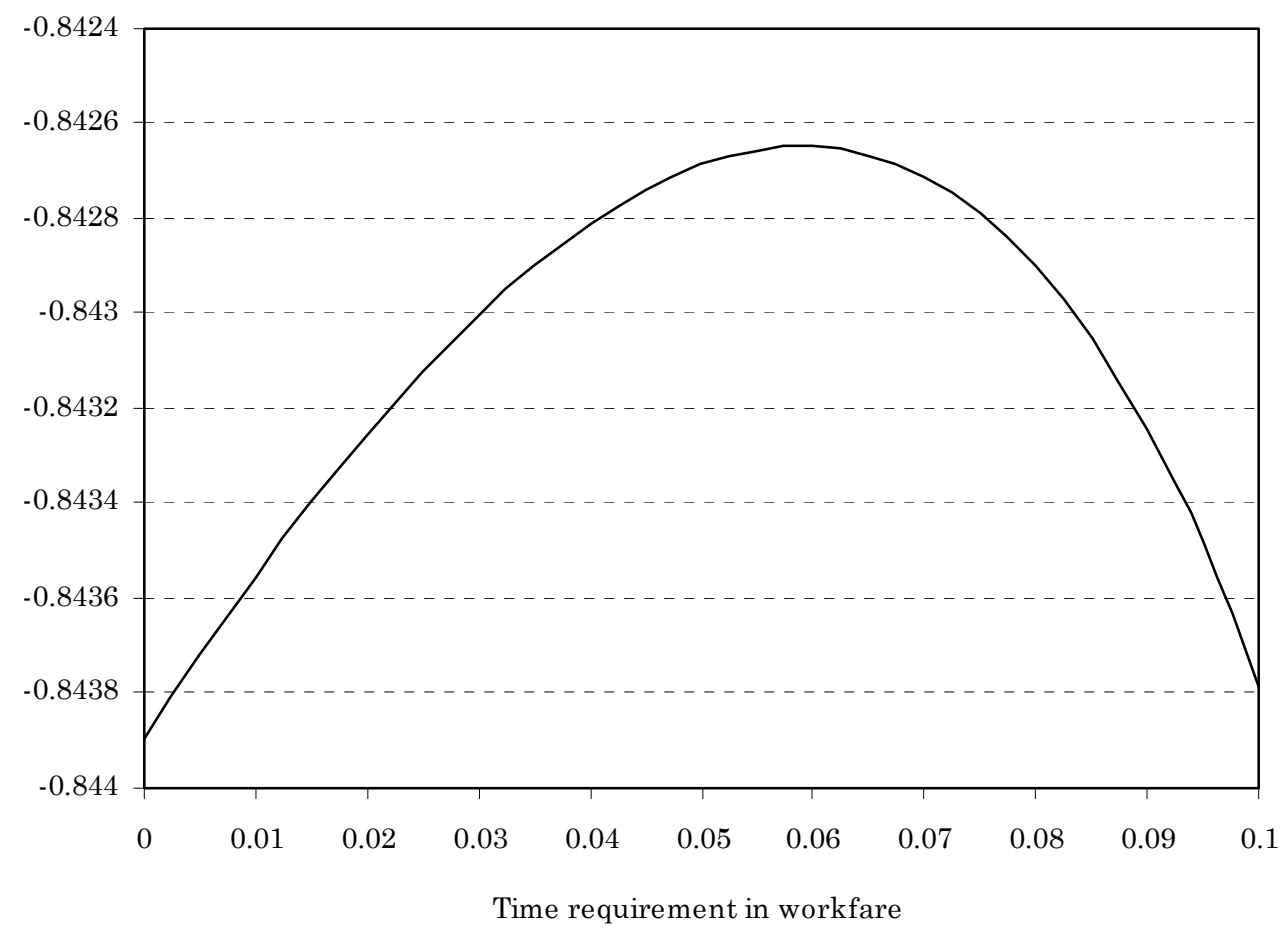

Column 2 of Table 4 reports a set of outcomes implied by an optimal system with workfare. Again, we give the corresponding outcomes with time limits in column 1 for ease of comparison. As shown in the table, the UI replacement rate is much lower with workfare than with time limits. This implies that search intensity on UI is higher than with time limits, despite the fact that workfare reduces the available time for other activities. The table also shows that the employment rate among workers is higher with workfare. Despite this workers 
would rather live in an optimal system with time limits. The reason for this result is that there is too little insurance with workfare.

\section{$\underline{3.5 \text { Choosing } \mu \text { optimally }}$}

All three experiments described above have treated $\mu$ as fixed at 0.5 . In the system with time limits, this corresponds to an expected duration of UI benefit receipt of two quarters; in the system with monitoring and sanctions, it means that insured workers are subjected to an inspection of search effort every second quarter; and in the system with workfare, $\mu=0.5$ implies that workers on UI will experience a work test every second quarter. A natural question is whether our results are sensitive to the choice of $\mu$ and whether there exists an optimal value of $\mu$.

Table 4: A benefit system with workfare

\begin{tabular}{lll}
\hline & $(1)$ & $(2)$ \\
& Time limits & Workfare \\
\hline \hline Policy variables & & \\
$B$ & 0.4621 & 0.3546 \\
$Z$ & 0.3016 & 0.3010 \\
$\mu$ & 0.5 & 0.5 \\
$P$ & 0 & 0.0591 \\
$\tau$ & 0.0538 & 0.0457 \\
Economic outcomes & & \\
$s_{w}^{u}$ & 0.4880 & 0.5630 \\
$s_{w}^{a}$ & 0.6099 & -- \\
$s_{w}^{p}$ & -- & 0.5326 \\
$u_{w}^{u}$ & 0.0529 & 0.0467 \\
$u_{w}^{a}$ & 0.0300 & -- \\
$u_{w}^{p}$ & -- & 0.0281 \\
$W$ & 0.8844 & 0.8862 \\
$\varepsilon$ & $0.55 \%$ & $0.12 \%$ \\
\hline \hline
\end{tabular}

Notes: Superindex $u, a$ and $p$ refer to UI, UA and workfare respectively. Remaining symbols are explained in the main text. $\mu$ is fixed at 0.5 . The welfare changes are measured relative to the base run.

In Fredriksson and Holmlund (2001) we have shown that there exists on interior solution with $\mu \in(0, \infty)$ in the system with time limits. Moreover, the analysis of monitoring and 
sanctions in Boone et al (2002) involves choosing $\mu$ optimally along with the other policy parameters. These features carry over to the present analysis, i.e., there exist interior solutions for $\mu$ in both the time limits and the monitoring-cum-sanctions system. ${ }^{7}$ However, it turns out that the optimal workfare system with $\mu$ chosen optimally along with $b$ and $p$ entails a positive but infinitesimally small value of $\mu$. To understand this result, note that a rise in $\mu$ means that workers receiving UI are transferred to a less favorable state at a higher rate, thus implying a first-order negative welfare effect. Other effects, such as the induced effects on tightness, may conceivably offset the first-order effect. In our simulation results, however, the potentially offsetting indirect effects are not sufficiently strong to offset the first-order effect. It thus follows that although $\mu$ must be strictly positive, is should be set as small as possible. Of course, a workfare system requires $\mu>0$, otherwise no screening would take place.

Figure 4 graphs the expected utility of workers as function of $\mu$ over the range $\mu \in(0,2]$. We consider four different systems, including the uniform one. Welfare is independent of $\mu$ in the uniform system for the obvious reason that a change of state does not change replacement rates.

The graph confirms our earlier reasoning. The UI systems featuring time limits and monitoring and sanctions have well defined interior solutions for $\mu$. The numbers suggest that the expected duration of UI benefit receipt should be around a quarter in a system with time limits and that workers should be monitored 1.3 times every quarter in a system with monitoring and sanctions. In a UI system with workfare, however, $\mu$ should be set as low as possible (but it must be interior); for values of $\mu$ in the excess of 1.6, it is no longer possible to design a system with workfare that screens out non-workers and the system collapses to a uniform one.

\footnotetext{
${ }^{7}$ This is of course unsurprising since the present model basically includes the previous ones as special cases.
} 
Figure 4: Worker expected utility as a function of $\mu$.

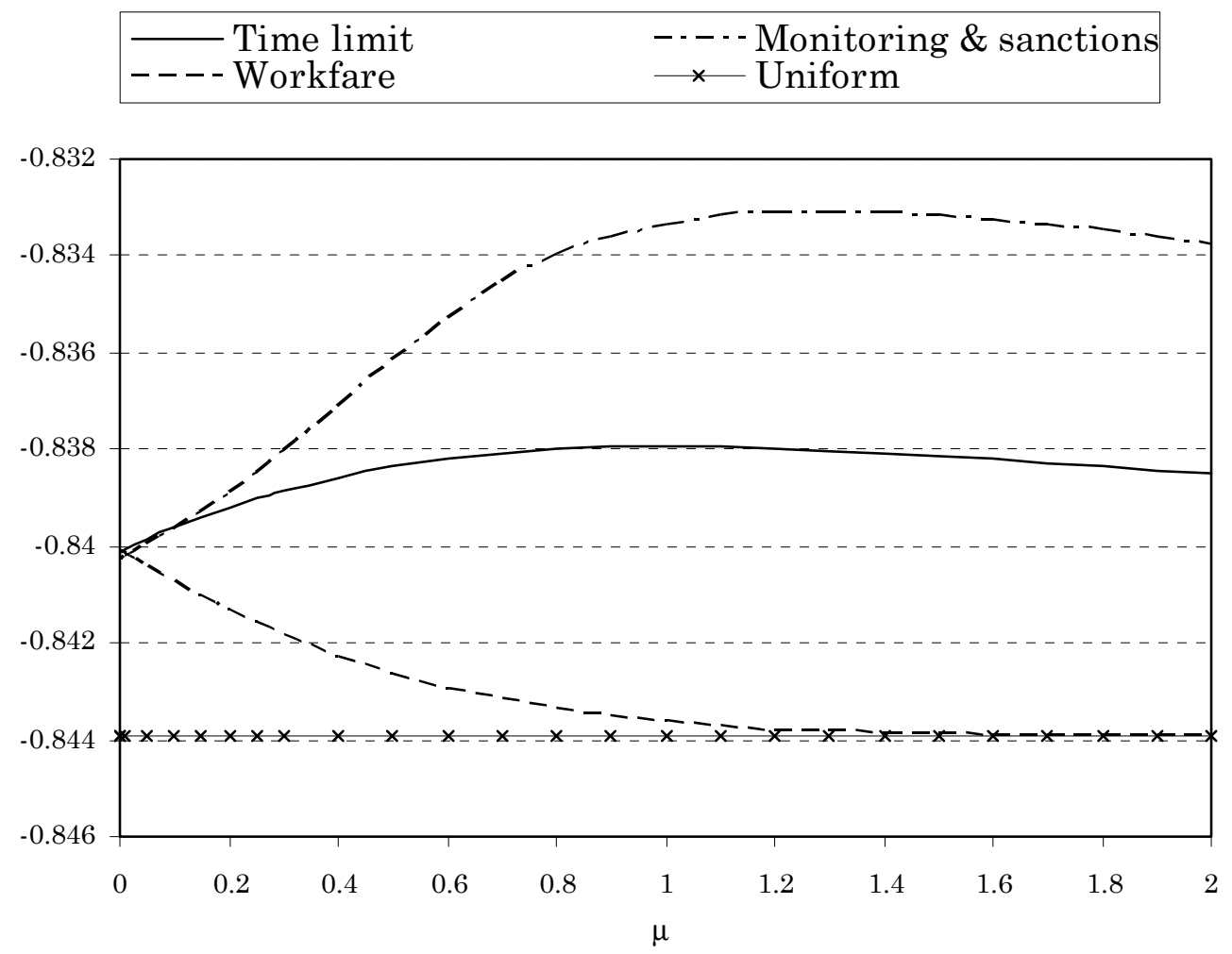

Figure 4 also conveys the message that a system with workfare never outperforms a system with time limits; they only become equivalent for arbitrarily small values of $\mu$ because then workers are never transferred to the least favored state. The question is whether this is a general lesson. We think it is, at least in the setting we are examining. The rationale for this conclusion is the following. Consider the most potent case for workfare. This must be when it is very easy to deter non-workers from claiming UI benefits. Thus, if the leisure value of nonworkers is infinitely high, the time requirement that screens out non-workers from the system can be arbitrarily small. Then workers are not penalized by being subjected to a work test. In this extreme case, workfare enables the UI provider to design what is effectively a uniform benefit system that is optimal for workers. In Fredriksson and Holmlund (2001) we showed that a system with time limits always dominates the optimal uniform system. Therefore, we are reasonably confident is saying that workfare can never outperform time limits, given that the duties performed on workfare are unproductive. Of course, matters would be different if there was some valuable production going on while participating in workfare. 


\section{Discussion}

The three measures that we have considered are alternative ways of refraining non-workers from claiming UI benefits. With these instruments, the UI provider can offer more generous compensation to workers. Workers will, therefore, prefer a UI system featuring time limits, monitoring and sanctions, or workfare to a system paying a constant wage replacement rate indefinitely.

The numerical analysis suggests a case for a monitoring and sanctions system. Since the system with monitoring and sanctions gives additional incentives to search, so as to avoid being transferred to UA, the UI provider can offer more insurance to the unemployed workers. One caveat to this conclusion may be that monitoring and sanctions raise the incentive to substitute formal search for informal search, as argued by van den Berg and van der Klaauw (2001). This is a complication that we have not considered in our numerical exercise. If informal and formal search are perfect substitutes then monitoring and sanctions will just be costly and bring no benefits in terms of restoring search incentives. Still it is difficult to believe that they are perfect substitutes; presumably there are some economies of scale of having search organized via the employment offices.

Another caveat in the case for monitoring and sanctions is that the costs of the system are difficult to estimate. Nevertheless, in Boone et al. (2002) we showed that the costs of introducing monitoring and sanctions would have to be implausibly large in order to overturn the conclusion that monitoring and sanctions is a welfare improvement relative to time limits.

The numerical results are less favorable to the case for workfare. Workfare is a perfect screening device, but it is not conducive to search. Therefore, the UI provider sets a lower UI replacement rate than in the systems with time limits and monitoring and sanctions. With preference heterogeneity as the only source of heterogeneity and unproductive workfare, we think that this conclusion applies fairly generally. 


\section{References}

Abbring, J, G van den Berg and J van der Ours (1998), The Effect of Unemployment Insurance Sanctions on the Transition Rate from Unemployment to Employment, Working Paper, Tinbergen Institute, Amsterdam.

Beaudry, P and C Blackorby (1998), Taxes and Employment Subsidies in Optimal Redistribution Programs, NBER Working Paper 6355.

Benus, J and T Johnson (1997), Evaluation of the Maryland Unemployment Insurance Work Search Demonstration. Report prepared for Maryland Department of Labor, Battelle Memorial Institute in conjunction with Abt Associates Inc. Available on the web at the address: http://wdr.doleta.gov/owsdrr/98-2/

Besley, T and S Coate (1992), Workfare versus Welfare: Incentive Arguments for Work Requirements in Poverty-Alleviation Programs, American Economic Review 82, 249-261.

Besley, T and S Coate (1995), The Design of Income Maintenance Programs, Review of Economic Studies 62, 187-221.

Black, D, J Smith, M Berger and B Noel (2003), Is the Threat of Training More Effective than Training Itself? Evidence from Random Assignment in the UI System, American Economic Review, forthcoming.

Blanchard O J and P Diamond (1989), The Beveridge Curve, Brookings Papers on Economic Activity 1:1989, 1-60.

Boone, J and J van Ours (2000), Modeling Financial Incentives to Get Unemployed Back to Work, CentER Discussion Paper 2000-02, Tilburg University.

Boone, J, P Fredriksson, B Holmlund and J van Ours (2002), Optimal Unemployment Insurance with Monitoring and Sanctions, Working Paper 2002:21, Institute for Labour Market Policy Evaluation (IFAU).

Cahuc, P and E Lehmann (2000), Should Unemployment Benefits Decrease with the Unemployment Spell? Journal of Public Economics 77, 135-153.

Davidson, C and S Woodbury (1997), Optimal Unemployment Insurance, Journal of Public Economics 64, 359-387.

Fredriksson, P and B Holmlund (2001), Optimal Unemployment Insurance in Search Equilibrium, Journal of Labor Economics 19, 370-399.

Fredriksson, P and B Holmlund (2003), Improving Incentives in Unemployment Insurance: A Review of Recent Research, Working Paper 2003:10, Department of Economics, Uppsala University.

Hansen, C T and T Tranæs (1999), Optimal Workfare in a Society of Workers and Nonworkers, manuscript, EPRU, University of Copenhagen.

Hopenhayn, H and J P Nicolini (1997), Optimal Unemployment Insurance, Journal of Political Economy 105, 412-38.

Hosios A J (1990), On the Efficiency of Matching and Related Models of Search and Unemployment, Review of Economic Studies 57, 279-98.

Jackman, R (1994), What Can Active Labour Market Policy Do? Swedish Economic Policy Review 1, 221-257. 
Johnson, T and D Klepinger (1994), Experimental Evidence on Unemployment Insurance Work-Search Policies, Journal of Human Resources 29, 695-717.

Lalive, R, J C van Ours and J Zweimüller (2002), The Effect of Benefit Sanction on the Duration of Unemployment, Discussion Paper 3311, Centre for Economic Policy Research.

Lundin, M (2000), Tillämpningen av arbetslöshetsförsäkringens regelverk vid arbetsförmedlingarna, stencil 2000:1, Institute for Labour Market Policy Evaluation (IFAU).

Mortensen, D (1977), Unemployment Insurance and Job Search Decisions, Industrial and Labor Relations Review 30, 505-517.

Shavell, S and L Weiss (1979), The Optimal Payment of Unemployment Insurance Benefits over Time, Journal of Political Economy 87, 1347-1362.

Van den Berg, G, B van der Klaauw and J van Ours (1998), Punitive Sanctions and the Transition Rate from Welfare to Work, Discussion Paper 9856, CentER for Economic Research, Tilburg University. Forthcoming in Journal of Labor Economics, 2004.

Van den Berg, G and B van der Klaauw (2001), Counseling and Monitoring of Unemployed Workers: Theory and Evidence from a Social Experiment, Working Paper 2001:12, Institute for Labour Market Policy Evaluation (IFAU).

Wang, C and S Williamson (1996), Unemployment Insurance with Moral Hazard in a Dynamic Economy, Carnegie Rochester Conference Series on Public Policy 44, 1-41 


\section{CESifo Working Paper Series}

(for full list see www.cesifo.de)

953 Hans Gersbach and Hans Haller, Competitive Markets, Collective Decisions and Group Formation, May 2003

954 Armin Falk, Urs Fischbacher, and Simon Gächter, Living in Two Neighborhoods Social Interactions in the LAB, May 2003

955 Margarita Katsimi, Training, Job Security and Incentive Wages, May 2003

956 Clemens Fuest, Bernd Huber, and Jack Mintz, Capital Mobility and Tax Competition: A Survey, May 2003

957 Edward Castronova, The Price of 'Man' and 'Woman': A Hedonic Pricing Model of Avatar Attributes in a Synthetic World, June 2003

958 Laura Bottazzi and Marco Da Rin, Financing Entrepreneurial Firms in Europe: Facts, Issues, and Research Agenda, June 2003

959 Bruno S. Frey and Matthias Benz, Being Independent is a Great Thing: Subjective Evaluations of Self-Employment and Hierarchy, June 2003

960 Aaron Tornell and Frank Westermann, Credit Market Imperfections in Middle Income Countries, June 2003

961 Hans-Werner Sinn and Wolfgang Ochel, Social Union, Convergence and Migration, June 2003

962 Michael P. Devereux, Measuring Taxes on Income from Capital, June 2003

963 Jakob de Haan, Jan-Egbert Sturm and Bjørn Volkerink, How to Measure the Tax Burden on Labour at the Macro-Level?, June 2003

964 Harry Grubert, The Tax Burden on Cross-Border Investment: Company Strategies and Country Responses, June 2003

965 Kirk A. Collins and James B. Davies, Measuring Effective Tax Rates on Human Capital: Methodology and an Application to Canada, June 2003

966 W. Steven Clark, Using Micro-Data to Assess Average Tax Rates, June 2003

967 Christopher Heady, The 'Taxing Wages' Approach to Measuring the Tax Burden on Labour, June 2003

968 Michael P. Devereux and Alexander Klemm, Measuring Taxes on Income from Capital: Evidence from the UK, June 2003 
969 Bernhard Eckwert and Itzhak Zilcha, The Effect of Better Information on Income Inequality, June 2003

970 Hartmut Egger and Josef Falkinger, The Role of Public Infrastructure for Firm Location and International Outsourcing, June 2003

971 Dag Morten Dalen and Trond E. Olsen, Regulatory Competition and Multi-national Banking, June 2003

972 Matthias Wrede, Tax Deductibility of Commuting Expenses and Residential Land Use with more than one Center, June 2003

973 Alessandro Cigno and Annalisa Luporini, Scholarships or Student Loans? Subsidizing Higher Education in the Presence of Moral Hazard, June 2003

974 Chang Woon Nam, Andrea Gebauer and Rüdiger Parsche, Is the Completion of EU Single Market Hindered by VAT Evasion?, June 2003

975 Michael Braulke and Giacomo Corneo, Capital Taxation May Survive in Open Economies, July 2003

976 Assar Lindbeck, An Essay on Welfare State Dynamics, July 2003

977 Henrik Jordahl and Luca Micheletto, Optimal Utilitarian Taxation and Horizontal Equity, July 2003

978 Martin D. D. Evans and Richard K. Lyons, Are Different-Currency Assets Imperfect Substitutes?, July 2003

979 Thorsten Bayindir-Upmann and Frank Stähler, Market Entry Regulation and International Competition, July 2003

980 Vivek Ghosal, Firm and Establishment Volatility: The Role of Sunk Costs, Profit Uncertainty and Technological Change, July 2003

981 Christopher A. Pissarides, Unemployment in Britain: A European Success Story, July 2003

982 Wolfgang Buchholz, Richard Cornes, and Wolfgang Peters, On the Frequency of Interior Cournot-Nash Equilibria in a Public Good Economy, July 2003

983 Syed M. Ahsan and Panagiotis Tsigaris, Choice of Tax Base Revisited: Cash Flow vs. Prepayment Approaches to Consumption Taxation, July 2003

984 Campbell Leith and Jim Malley, A Sectoral Analysis of Price-Setting Behavior in US Manufacturing Industries, July 2003

985 Hyun Park and Apostolis Philippopoulos, Choosing Club Membership under Tax Competition and Free Riding, July 2003 
986 Federico Etro, Globalization and Political Geography, July 2003

987 Dan Ariely, Axel Ockenfels and Alvin E. Roth, An Experimental Analysis of Ending Rules in Internet Auctions, July 2003

988 Paola Conconi and Carlo Perroni, Self-Enforcing International Agreements and Domestic Policy Credibility, July 2003

989 Charles B. Blankart and Christian Kirchner, The Deadlock of the EU Budget: An Economic Analysis of Ways In and Ways Out, July 2003

990 M. Hasham Pesaran and Allan Timmermann, Small Sample Properties of Forecasts from Autoregressive Models under Structural Breaks, July 2003

991 Hyun Park, Apostolis Philippopoulos and Vangelis Vassilatos, On the Optimal Size of Public Sector under Rent-Seeking competition from State Coffers, July 2003

992 Axel Ockenfels and Alvin E. Roth, Late and Multiple Bidding in Second Price Internet Auctions: Theory and Evidence Concerning Different Rules for Ending an Auction, July 2003

993 Pierre Salmon, The Assignment of Powers in an Open-ended European Union, July 2003

994 Louis N. Christofides and Chen Peng, Contract Duration and Indexation in a Period of Real and Nominal Uncertainty, July 2003

995 M. Hashem Pesaran, Til Schuermann, Björn-Jakob Treutler, and Scott M. Weiner, Macroeconomic Dynamics and Credit Risk: A Global Perspective, July 2003

996 Massimo Bordignon and Sandro Brusco, On Enhanced Cooperation, July 2003

997 David F. Bradford, Addressing the Transfer-Pricing Problem in an Origin-Basis X Tax, July 2003

998 Daniel Gros, Who Needs Foreign Banks?, July 2003

999 Wolfram Merzyn and Heinrich W. Ursprung, Voter Support for Privatizing Education: Evidence on Self-Interest and Ideology, July 2003

1000 Jo Thori Lind, Fractionalization and the Size of Government, July 2003

1001 Daniel Friedman and Donald Wittman, Litigation with Symmetric Bargaining and TwoSided Incomplete Information, July 2003

1002 Matthew Clarke and Sardar M. N. Islam, Health Adjusted GDP (HAGDP) Measures of the Relationship Between Economic Growth, Health Outcomes and Social Welfare, July 2003

1003 Volker Grossmann, Contest for Attention in a Quality-Ladder Model of Endogenous Growth, August 2003 
1004 Marcel Gérard and Joan Martens Weiner, Cross-Border Loss Offset and Formulary Apportionment: How do they affect multijurisdictional firm investment spending and interjurisdictional tax competition?, August 2003

1005 Burkhard Heer, Nonsuperneutrality of Money in the Sidrauski Model with Heterogeous Agents, August 2003

1006 V. Anton Muscatelli, Piergiovanna Natale, and Patrizio Tirelli, A Simple and Flexible Alternative to the Stability and Growth Pact Deficit Ceilings. Is it at hand?, August 2003

1007 Reto Foellmi and Josef Zweimüller, Inequality and Economic Growth: European Versus U.S. Experiences, August 2003

1008 James S. Costain and Michael Reiter, Business Cycles, Unemployment Insurance, and the Calibration of Matching Models, August 2003

1009 Marco Runkel, Optimal Contest Design when the Designer's Payoff Depends on Competitive Balance, August 2003

1010 Donald O. Parsons, Torben Tranaes and Helene Bie Lilleør, Voluntary Public Unemployment Insurance, August 2003

1011 Rüdiger Pethig and Andreas Wagener, Profit Tax Competition and Formula Apportionment, August 2003

1012 Johan Willner, Privatisation and Public Ownership in Finland, August 2003

1013 Seppo Kari and Jouko Ylä-Liedenpohja, Taxation and Valuation of International Real Investments, August 2003

1014 James Heckman, Rosa Matzkin and Lars Nesheim, Simulation and Estimation of Hedonic Models, August 2003

1015 Biswa N. Bhattacharyay, Towards a Macro-Prudential Leading Indicators Framework for Monitoring Financial Vulnerability, August 2003

1016 J. Stephen Ferris and Stanley L. Winer, Searching for Keynes: With Application to Canada, 1870-2000, August 2003

1017 Massimo Bordignon, Luca Colombo and Umberto Galmarini, Fiscal Federalism and Endogenous Lobbies' Formation, August 2003

1018 Annette Alstadsæter, The Dual Income Tax and Firms'Income Shifting through the Choice of Organizational Form and Real Capital Investments, August 2003

1019 Peter Fredriksson and Bertil Holmlund, Optimal Unemployment Insurance Design: Time Limits, Monitoring, or Workfare?, August 2003 